\title{
CT Brain in Children: Evaluation of the Clinical and Radiological Findings
}

\author{
Awad Elkhadir'1, Mohamed Gotb², Deema Hussein ${ }^{3}$, Mohamad Saka ${ }^{3}$, Saddiq Jastaniah ${ }^{1}$ \\ ${ }^{1}$ Diagnostic Radiology Department, Faculty of Applied Medical Sciences (FAMS), King Abdulaziz University \\ (KAU), Jeddah, Saudi Arabia \\ ${ }^{2}$ Department of Diagnostic Radiology, King Abdulaziz University Hospital (KAUH), Jeddah, Saudi Arabia \\ ${ }^{3}$ King Fahd Medical Research Centre, King Abdulaziz University (KAU), Jeddah, Saudi Arabia \\ Email: sjastaniah@kau.edu.sa
}

Received 5 January 2016; accepted 4 March 2016; published 8 March 2016

Copyright (C) 2016 by authors and Scientific Research Publishing Inc.

This work is licensed under the Creative Commons Attribution International License (CC BY).

http://creativecommons.org/licenses/by/4.0/

(c) (i) Open Access

\begin{abstract}
This study was done to the review and documentation of brain CT investigations in King Abdulaziz University Hospital (KAUH), Jeddah, Saudi Arabia in 2012 including CT findings for brain based on justifications for scan. The purpose of the study is to evaluate the situation of requesting CT brain versus the reporting findings. A retrospective study was carried out in the Department of Radiology, KAUH between 1 January and 31 December 2012. There were 417 children scanned by CT for brain, their data were reviewed and analyzed from radiology records to form the sample of the study. The study revealed that high percentages of radiological findings for CT brain did not confirm the clinical diagnosis. The percentages of such cases which observed in the three departments of emergency, inpatient and outpatient were $68.4 \%, 53.6 \%$ and $49.4 \%$ respectively. This result shows that a percentage of children were given unnecessary exposure to radiation among those who received CT brain from the radiology department in KAUH. From the study, it is concluded that most brain CT done for children were not justification as well as there were more brain CT findings not confirmed the clinical diagnosis, although the brain CT may be significant in most of the cases. Hence, there is a big concern about the increasing requests for unnecessary brain CT. Therefore, the paediatricians should be more careful in requesting of brain CT unless it is indispensible.
\end{abstract}

\section{Keywords}

CT Brain, Radiology, Children, Clinical Diagnosis

\section{Introduction}

The uses of computed tomography (CT) scan have seen increased in children in contemporary times. CT has 
brought significant changes in the diagnosis of diseases. Since the advert of CT into clinical practice in 1973 [1], there has been an exponential increase in the number of CT scanners and the frequency of CT examinations [2] [3]. A major drawback of CT is the use of ionizing radiation and consequently, the risks of radiation-induced side effects [4] [5]. Of these side effects, the induction of cancer is the most important. This is especially true in children because rapidly dividing cells are more sensitive to radiation, the tissues of children are up to 10 times more radiosensitive than those of adults [6].

The King Abdul Aziz University Hospital (KAUH) is one such health institution and foundation where the health service and education is provided for patient, students, physician and trainees to obtain what they need. For literature searching, in the UK, in 2008, according to the latest multi-center survey, CT has grown in frequency from 5\% to $11 \%$ compared with 10 years earlier. Despite this relatively low frequency of examinations, compared to radiography and fluoroscopy, CT is the growing and dominant contributor to the total collective effective dose from X-ray examinations being responsible for around $68 \%$ of the total collective dose, compared to $40 \%$ in 1998 , while the percentage contribution from radiographic and fluoroscopic examinations has nearly halved [7]. CT is frequently used in children to look for clinically-important traumatic brain injury (ciTBI) [8] [9]. There is a body of research showing the potential deleterious effects of medical radiation exposure to children, especially radiation to the brain [10] [11]. Multiple clinical decision rules were developed to attempt to identify children at low risk for intracranial injury following blunt head trauma as a way to avoid unnecessary radiation [12] [13]. Yet, the indications for CT in these children remained controversial [10] [14] [15].

American College of Radiology “ACR Appropriateness Criteria”, and the referral guidelines of The Royal College of Radiologists help the clinician (and radiologist) in deciding which imaging modality is the best for specific indications [16] [17].

A recent study on June 6, 2012 showed radiation exposure from two or three head CT scans in childhood giving a cumulative dose of around $60 \mathrm{mGy}$ can triple the risk of developing brain cancer, while five to 10 such scans (cumulative dose around $50 \mathrm{mGy}$ ) may triple the risk of developing leukemia, according to a major study published online June 7 in Lancet [18].

This is an exploration to understand the request form of the brain CT of children in the diagnostic radiology department, KAUH, Saudi Arabia. The purpose of this study is to evaluate the clinical diagnosis of brain CT and CT findings.

\section{Materials and Methods}

The current study is a retrospective was done after ethical approval was obtained of the Chairman of ethics and research committee in the KAUH.

CT brain reports of 417 brains CT in the diagnostic radiology department in the KAUH, between 1 January and 31 December 2012, were scanned and followed CT protocol taken through this study by the use of 128 Somatom CT machine as described in Table 1.

Table 1. Protocols of CT brain examination.

\begin{tabular}{cc}
\hline Protocol & Brain sequence-child \\
\hline Detector collimation & $12 \times 1.2 \mathrm{~mm}$ \\
KVp & $120 \mathrm{kv}$ \\
Cffective mAs & $4-8 \mathrm{~mm}$ \\
Slice & $\mathrm{NA}$ \\
Rotation time & $\mathrm{NA}$ \\
Scan time & $\mathrm{NA}$ \\
Pitch & 2 Sec \\
Delay & $14 \mathrm{~mm}$ \\
Feed & \\
Comments & Send to Picture Archiving and Communication System (PACS) Tomogram. AXIAL 4.8 mm Keinel H \\
& If Medium/window cerebrum.
\end{tabular}


417 children formed the sample of the study, of which 222 were male and 195 female. The inclusion criterion for the study was to be a part of the diagnostic radiology department in the KAUH. The children were divided in 4 different age groups (less than 1, 1 - 5, 6 - 10, 11 - 15 years old). Frequency were used to describe the general and presenting characteristics in the children and among those who received brain CT scans, divided by three locations were include: first for Emergency, the second for Inpatient, and the third for Outpatient. Adjustment for multiple comparisons was performed. There were no other inclusion/exclusion criteria laid out for the study. The data obtained was validated for completeness and consistency and analysed quantitatively using the statistical package SPSS and Microsoft Excel.P value was considered to be significant if it was $<0.05$ and the results were gathered to look at the trends that emerged from the data with regard to the radiology electronic recording system. The results of the study are presented in the form of tables as included later in the study.

\section{Results}

The vast majority of pediatrics scanned with CT was male 222 (53.2\%) while females were 195 (46.8\%). Also study shows the the highest percentage was in the age of 1 - 5 years old (33.2\%) (Table 2). Apart from these demographic data, the focus of the study was primarily the trends related to the CT brain findings which were positive or negative regarding to the clinical diagnosis. It was found out from the data gathered that majority of brain CT findings did not confirm the clinical diagnosis through departments of emergency, inpatient and out patient 106 (68.4\%), 98 (53.6\%) and 39 (49.4\%) respectively Table 3. Statistically significant differences were found for brain CT P value 0.005 . This indicates that more than the half of the CT findings for brain did not confirm the reasons for exam, although, this clinical diagnosis might be reasonable for request brain CT. The most common clinical diagnosis (reason of exam) among 417 brain CT were 90 (21.58\%) Trauma/Cerebrovascular Accident (CVA) for brain (Table 4).

Statistically significant differences were found for brain CT. This indicates that more than the half of the CT findings for brain not confirmed the reasons for exam. Thus, the results indicate that a significant variable in the decision to order CT brain for children in the diagnostic radiology department in KAUH. The most common clinical diagnosis (reason of exam) among 417 brains CT was 90 (21.58\%) Trauma/Cerebrovascular Accident (CVA) for brain Table 4.

\section{Discussion}

The study indicated towards the trends of imaging of the brain by CT for children in the diagnostic radiology

Table 2. The sex and age groups distribution between 417 children.

\begin{tabular}{cccc}
\hline Category & & Number & Percentage \% \\
Gender & Male & 222 & 53.2 \\
& Female & 195 & 46.8 \\
Total & & 417 & 100.0 \\
Age (Years) & Number & 85 & Percentage \% \\
Under 1 & 138 & 20.3 \\
$1-5$ & & 98 & 33.2 \\
$6-10$ & 96 & 23.5 \\
$11-15$ & 417 & 23.0 \\
Total & & & 100.0 \\
\hline
\end{tabular}

Table 3. Showed comparative data.

\begin{tabular}{ccccc}
\hline Pediatrics location & Confirmed number and (Percentage) & Not confirmed number and percentage & Total & P value \\
\cline { 2 - 5 } Emergency & $49(31.6)$ & $106(68.4)$ & 155 \\
Inpatient & $85(46.4)$ & $98(53.6)$ & 183 & 0.005 \\
Outpatient & $40(50.6)$ & $39(49.4)$ & 79 & - \\
- & 174 & 243 & 417 & - \\
\hline
\end{tabular}


Table 4. Clinical diagnosis (reason of exam) for CT-Brain.

\begin{tabular}{|c|c|c|c|c|c|}
\hline $\begin{array}{c}\text { Clinical diagnosis } \\
\text { (reason for examination) }\end{array}$ & $\begin{array}{c}\text { Frequency } \\
\text { (number of patients) }\end{array}$ & Percentage & $\begin{array}{c}\text { Clinical diagnosis } \\
\text { (reason for examination) }\end{array}$ & $\begin{array}{c}\text { Frequency } \\
\text { (number of patients) }\end{array}$ & Percentage \\
\hline Trauma/CVA & 90 & 21.58 & Myelomeningocele post repair & 2 & 0.48 \\
\hline Convulsion/Seizure & 61 & 14.63 & Apnea & 2 & 0.48 \\
\hline Hydrocephalus & 40 & 9.59 & Encephalopathy & 2 & 0.48 \\
\hline For follow up & 39 & 9.35 & Sepsis/For more evaluation) & 2 & 0.48 \\
\hline Brain edema/insult & 32 & 7.67 & Fever & 2 & 0.48 \\
\hline VP-Shunt & 20 & 4.80 & Willebrand disease & 1 & 0.24 \\
\hline Headache & 16 & 3.84 & Post/pre Chemotherapy & 1 & 0.24 \\
\hline $\begin{array}{c}\text { Intracranial } \\
\text { hemorrhage/hematoma }\end{array}$ & 15 & 3.60 & Bony calvariumabnormality & 1 & 0.24 \\
\hline Mass/Swelling & 14 & 3.58 & Mental Retardation aggression & 1 & 0.24 \\
\hline $\begin{array}{l}\text { Uprolling of eyes and loss } \\
\text { of conscious }\end{array}$ & 11 & 2.64 & Dermoid cyst & 1 & 0.24 \\
\hline $\begin{array}{l}\text { Delay speech and } \\
\text { response }\end{array}$ & 10 & 2.40 & Post fenestration & 1 & 0.24 \\
\hline Limbs weakness & 7 & 1.68 & Brain infarct & 1 & 0.24 \\
\hline $\begin{array}{c}\text { Dyspnea and involuntary } \\
\text { movement }\end{array}$ & 6 & 1.44 & Intracranial pressure & 1 & 0.24 \\
\hline Craniosynostosis & 5 & 1.20 & Facial atrophy & 1 & 0.24 \\
\hline Brain herniation & 5 & 1.20 & Due to birth asphyxia & 1 & 0.24 \\
\hline Meningitis & 5 & 1.20 & Disorientation & 1 & 0.24 \\
\hline Brain abscess & 4 & 0.96 & Metabolic disorder & 1 & 0.24 \\
\hline Epileptics & 2 & 0.48 & Encephalitis & 1 & 0.24 \\
\hline Facial palsy & 2 & 0.48 & Rigid neck & 1 & 0.24 \\
\hline Thrombi embolic & 2 & 0.48 & $\begin{array}{l}\text { Bony destruction for new } \\
\text { surgery evaluation }\end{array}$ & 1 & 0.24 \\
\hline Aneurysm & 2 & 0.48 & Hypoxic Ischemic & 1 & 0.24 \\
\hline Facial asymmetry & 2 & 0.48 & Microcephaly & 1 & 0.24 \\
\hline Total & 390 & 93.76 & $(\mathrm{n}=417) 100 \%$ & 27 & 6.48 \\
\hline
\end{tabular}

department, KAUH. The results of the study can be seen as similar to what have been reported in similar studies by other researchers. Previous studies related to the derivation and validation of clinical decision rules have shown a 3\% - 62\% rate of CT scanning, [13] [19] [20] a 1.2\% - 8.3\% rate of ciTBI [12] [13] [19] [21].

Patients in these studies were primarily seen in academic and pediatric EDs with more significant mechanisms of injury [12] [15] [21] [22]. The PECARN study had a 35\% rate of CT use and $0.9 \%$ ciTBI rate [23].

As reported in this study $68.4 \%$ of brain CT findings did not confirm the clinical diagnosis in the emergency department. An earlier study led by Kuppermann and published by the Lancet in (2009) developed and validated a traumatic brain injury prediction rule to identify children at low risk for clinically important head injuries who probably do not require CT evaluation [24]. The current study also revealed that $21.58 \%$ of the indications of brain CT were head trauma; this is also in agreement with Hajo Zeeb (2012) in his study in Germany demonstrated the most frequent indications for a CT examination in children were trauma [25]. Related to the Triage, assessment, investigation and early management of head injury in children recently the National Institute for Health and Care Excellence (NICE) Issued(January 2014) an important clinical guideline 176 rather to pediatricians to read and follow it carefully before ordering any CT examinations to the children [26]. Our study has some limitations, because this was a retrospective cohort study and the smaller sample size in patients made it difficult to assess the variables associated with CT use in children. To sum up, brain CT scans in children dra- 
matically increased to confirm or negate the clinical diagnosis.

\section{Conclusion}

This study emphasizes that brain CT utilization must be associated with justification for scan in children. It is important that pediatricians should not order brain CT unless it is indispensable. It is no doubt true that health professionals work together to minimize the radiation dose to children. But it is recommended that it is very important for pediatricians, radiologist and $\mathrm{x}$-ray technologist to put their minds on the three unique considerations in children: Children are considerably more sensitive to radiation than adults, as demonstrated in epidemiologic studies of exposed populations; children have a longer life expectancy than adults, resulting in a larger window of opportunity for expressing radiation damage and children may receive a higher radiation dose than necessary if CT settings are not adjusted for their smaller body size [27].

\section{References}

[1] Hounsfield, G.N. (1973) Computerized Transverse Axial Scanning (Tomography). Part 1. Description of System. The British Journal of Radiology, 46, 1016-1022. http://dx.doi.org/10.1259/0007-1285-46-552-1016

[2] Shannoun, F., Zeeb, H., Back, C. and Blettner, M. (2006) Medical Exposure of the Population from Diagnostic Use of Ionizing Radiation in Luxembourg between 1994 and 2002. Health Physics, 91, 154-162. http://dx.doi.org/10.1097/01.HP.0000205237.00357.58

[3] UNSCEAR United Nations Scientific Committee on the Effects of Atomic Radiation (2010) Sources and Effects of Ionizing Radiation. Report to the General Assembly with Scientific Annexes, Vol. I. UNSCEAR, New York.

[4] Slovis, T.L. (2002) The ALARA (as Low as Reasonably Achievable) Concept in Pediatric CT Intelligent Dose Reduction. ALARA Conference Proceedings. Pediatric Radiology, 32, 217-218. http://dx.doi.org/10.1007/s00247-002-0669-8

[5] Berrington de González, A., Mahesh, M., Kim, K.P., et al (2009) Projected Cancer Risks from Computed Tomography Scans Performed in the United States in 2007. Archives of Internal Medicine, 169, 2071-2077. http://dx.doi.org/10.1001/archinternmed.2009.440

[6] Brenner, D., Elliston, C., Hall, E. and Berdon, W. (2001) Estimated Risks of Radiation-Induced Fatal Cancer from Pediatric CT. AJR American Journal of Roentgenology, 176, 289-296. http://dx.doi.org/10.2214/ajr.176.2.1760289

[7] Hart, D., Wall, B.F., Hillier, M.C. and Shrimpton, P.C. (2010) Frequency and Collective Dose for Medical and Dental X-Ray Examinations in the UK, 2008. HPA-CRCE-012, Chilton, Didcot.

[8] Homer, C.J. and Kleinman, L. (1999) Technical Report: Minor Head Injury in Children. Pediatrics, 104, e78. http://dx.doi.org/10.1542/peds.104.6.e78

[9] Simon, B., Letourneau, P., Vitorino, E. and McCall, J. (2001) Pediatric Minor Head Trauma: Indications for Computed Tomographic Scanning Revisited. Journal of Trauma, 51, 231-237.

[10] (2002) FDA Public Health Notification: Reducing Radiation Risk from Computed Tomography for Pediatric and Small Adult Patients. Pediatric Radiology, 32, 314-316. http://dx.doi.org/10.1007/s00247-002-0687-6

[11] Hall, P., Adami, H.O., Trichopoulos, D., Pedersen, N.L., Lagiou, P., Ekbom, A., et al. (2004) Effect of Low Doses of Ionising Radiation in Infancy on Cognitive Function in Adulthood: Swedish Population Based Cohort Study. BMJ, 328, 19.

[12] Atabaki, S.M., Stiell, I.G., Bazarian, J.J., Sadow, K.E., Vu, T.T., Camarca, M.A., et al. (2008) A Clinical Decision Rule for Cranial Computed Tomography in Minor Pediatric Head Trauma. Archives of Pediatrics and Adolescent Medicine, 162, 439-445. http://dx.doi.org/10.1001/archpedi.162.5.439

[13] Palchak, M.J., Holmes, J.F., Vance, C.W., Gelber, R.E., Schauer, B.A., Harrison, M.J., et al. (2003) A Decision Rule for Identifying Children at Low Risk for Brain Injuries after Blunt Head Trauma. Annals of Emergency Medicine, 42, 492-506. http://dx.doi.org/10.1067/S0196-0644(03)00425-6

[14] Maguire, J.L., Boutis, K., Uleryk, E.M., Laupacis, A. and Parkin, P.C. (2009) Should a Head Injured Child Receive a Head CT Scan? A Systematic Review of Clinical Prediction Rules. Pediatrics, 124, e145-e154. http://dx.doi.org/10.1542/peds.2009-0075

[15] Schnadower, D., Vazquez, H., Lee, J., Dayan, P. and Roskind, C.G. (2007) Controversies in the Evaluation and Management of Minor Blunt Head Trauma in Children. Current Opinion in Pediatrics, 19, 258-264. http://dx.doi.org/10.1097/MOP.0b013e3281084e85

[16] American College of Radiology ACR (2008) ACR Appropriateness Criteria, October 2008 Version. http://www.acr.org/default.aspx 
[17] The Royal College of Radiologists (2009) Making the Best Use of Clinical Radiology Services, Referral Guidelines. 6th Edition (MBUR6). http://www.rcr.ac.uk

[18] http://www.auntminnie.com/index.aspx?sec=sup n\&sub=cto\&pag=dis\&ItemID=99583.

[19] Dunning, J., Daly, J.P., Lomas, J.P., Lecky, F., Batchelor, J. and Mackway-Jones, K. (2006) Derivation of the Children's Head Injury Algorithm for the Prediction of Important Clinical Events Decision Rule for Head Injury in Children. Archives of Disease in Childhood, 91, 885-891. http://dx.doi.org/10.1136/adc.2005.083980

[20] Oman, J.A., Cooper, R.J., Holmes, J.F., Viccellio, P., Nyce, A., Ross, S.E., et al. (2006) Performance of a Decision Rule to Predict Need for Computed Tomography among Children with Blunt Head Trauma. Pediatrics, 117, e238-e246. http://dx.doi.org/10.1542/peds.2005-1063

[21] Haydel, M.J. and Shembekar, A.D. (2003) Prediction of Intracranial Injury in Children Aged Five Years and Older with Loss of Consciousness after Minor Head Injury due to Nontrivial Mechanisms. Annals of Emergency Medicine, 42, 507-514. http://dx.doi.org/10.1067/S0196-0644(03)00512-2

[22] Teasdale, G. and Jennett, B. (1974) Assessment of Coma and Impaired Consciousness. A Practical Scale. Lancet, 304, 81-84. http://dx.doi.org/10.1016/S0140-6736(74)91639-0

[23] Kuppermann, N., Holmes, J.F., Dayan, P.S., Hoyle Jr., J.D., Atabaki, S.M., Holubkov, R., et al. (2009) Identification of Children at Very Low Risk of Clinically-Important Brain Injuries after Head Trauma: A Prospective Cohort Study. Lancet, 374, 1160-1170. http://dx.doi.org/10.1016/S0140-6736(09)61558-0

[24] http://www.futurity.org/kids-head-trauma-ct-scans-729022/

[25] http://www.biomedcentral.com/1472-6963/12/47

[26] https://www.nice.org.uk/

[27] http://www.cancer.gov/cancertopics/causes/radiation/radiation-risks-pediatric-CT 